\title{
NESQUEHONITE FROM YOSHIKAWA, AICHI PREFECTURE, JAPAN : OCCURRENCE AND THERMAL BEHAVIOUR
}

\author{
Jujin Suzuki* and Masahiro Ito**
}

* Department of Earth Sciences, Aichi University of Education, Kariya.

** Laboratory of Earth Sciences, Department of General Education, Nagoya University, Nagoya.

\begin{abstract}
Nesquehonite, $\mathrm{MgCO}_{3} \cdot 3 \mathrm{H}_{2} \mathrm{O}$, from Yoshikawa, Aichi Prefecture, the first occurrence in Japan is described. It is found as columnar aggregates covering the encrustment of "yoshikawaite" on the weathered surface of the serpentinite. The X-ray diffraction pattern and the optical properties are identical to those of the previous data.

The nesquehonite is thermally decomposed lastly to periclase through the three intermediate phases, that is, the dehydirate phase $\left(80-200^{\circ} \mathrm{C}\right)$, the amorphous phase $\left(210-270^{\circ} \mathrm{C}\right)$ and the decarbonate phase $\left(280-480^{\circ} \mathrm{C}\right)$. Periclase is produced at $370^{\circ} \mathrm{C}$. A few absorption bands characteristic of the decarbonate phase are already found in the infrared spectrum of the amorphous phase.

DTA curve for nesquehonite shows six endotherms with maxima at $132,176,216$, 420, 507 and $526^{\circ} \mathrm{C}$, respectively, and an exotherm at $499^{\circ} \mathrm{C}$. The first three endotherms are attributed to the removal of $\mathrm{H}_{2} \mathrm{O}$, and the others to that of $\mathrm{CO}_{2}$. The exothermic reaction is considered to be coupled with the fifth endothermic one.
\end{abstract}

\section{INTRODUGTION}

Nesquehonite, $\mathrm{MgCO}_{3} \cdot 3 \mathrm{H}_{2} \mathrm{O}$, one of the simple magnesium carbonate hydrate minerals, from Yoshikawa, Aichi Prefecture was found for the first time in Japan. The Xray diffraction, DTA curves and optical properties are identified with those of the nesquehonite reported by other workers. It occurs closely associated with an unusual magnesium carbonate hydrate mineral, $\mathrm{Mg}_{5}$ $\left(\mathrm{CO}_{3}\right)_{4}(\mathrm{OH})_{2} \cdot 8 \mathrm{H}_{2} \mathrm{O}$,*** which covers the serpentinite body as the encrustment, having a characteristically long spacing of $33.2 \dot{A}$ (Suzuki and Ito, 1973). Other natural occurrences of nesquehonite are, for example, (1) in cauliflower-like rough crust on the small wall of upper Juarssic dolostone cave of West Germany, admixed with hydro- magnesite and trace of monohydrocalcite, calcite and aragonite (Fischbeck and Müller, 1971), (2) in serpentinite, (3) in coal mine (Winchell and Winchell, 1951) and so on. It was also found even in the carbonate scales in the air scrubber of an air-conditioning plant, associated with hydrocalcite and calcite (Marschner, 1969). A mixture of nesquehonite and aragonite was reported to be formed from the sea-water by the vapour phase diffusion technique (Towe and Malone, 1970).

Some mineralogical and crystallographical studies of nesquehonite have been reported, most of which were done for synthesized specimens. Stephan and Macgillavry (1972) determined the crystal structure of nesquehonite synthesized by the method of

*** Application for an approval of the name, "yoshikawaite," is pending.

(Manuscript received, April 15, 1974) 
Menzel and Brückner. Since it has some noticeable behaviour indicating the change into periclase due to thermal decomposition, keen attention has been paid. It passes through the stages accompanied by a few intermediate phases (Morandi, 1969; Iwai et al., 1969).

In this paper, the occurrence and the thermal behaviour of nesquehonite from Yoshikawa will be presented in detail based on the characteristics in X-ray diffraction patterns, DTA-TG curves and infrared spectra.

The optical properties of nesquehonite are as follows: $\alpha<1.448, \beta=1.504, \gamma=$ $1.528 ; \gamma-\alpha>0.080, \gamma-\beta=0.024$. It is colourless and shows nearly straight extinction with positive elongation.

\section{Mode of OGGURRENGE}

Nesquehonite is nearly colourless and transparent, and slender column-like crystals (Fig. 1). It occurs as columnar aggregates growing perpendicular to the surface of the encrustment of "yoshikawaite" covering the serpentinite body (Fig. 2).

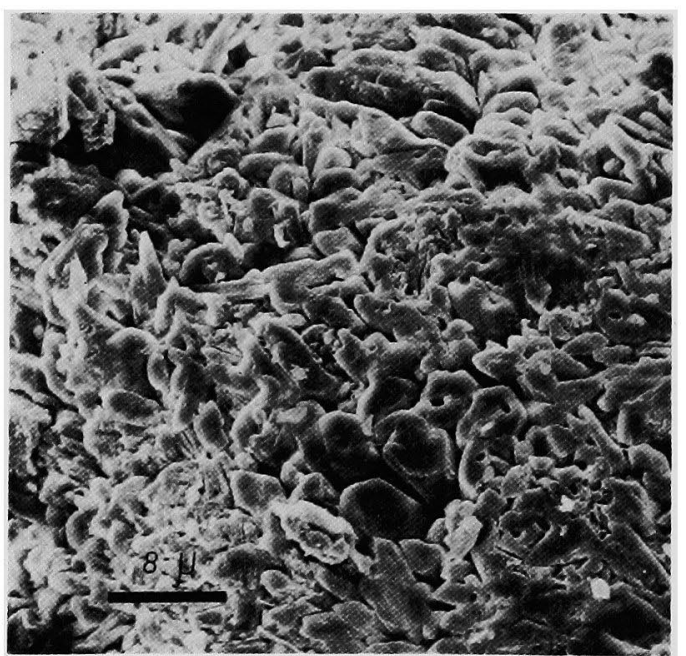

Fig. 1. Scanning electron microphotograph of nesquehonite.
The serpentinite body contains some amounts of brucite and is conspicuously carbonate-hydrated, forming hydrotalcite group-mineral, hydromagnesite and artinite. Aragonite and hydromagnesite coexist also as vein-fillings in the serpentinite. As reported in the previous paper (Suzuki and Ito, 1973), the encrustment of "yoshikawaite" is an evaporation product, on the surface of the cutting cliff, from the groundwater near the surface which dissolves brucite, hydrotalcite group-mineral and the related minerals. This unusual "yoshikawaite" is slightly soluble even in distilled water and is more soluble in rain water. Judging from the occurrences, nesquehonite is also considered to be an evaporation product on the surface of "yoshikawaite" mainly from rain water which dissolves the latter mineral. Brucite, hydrotalcite group-mineral, hydromagnesite and other magnesium carbonate hydrate minerals are soluble slightly in the water with dissolved $\mathrm{CO}_{2}$. Nesquehonite is observed to be formed by evaporation from such a solution at room temperature. However, in Yoshikawa nesquehonite

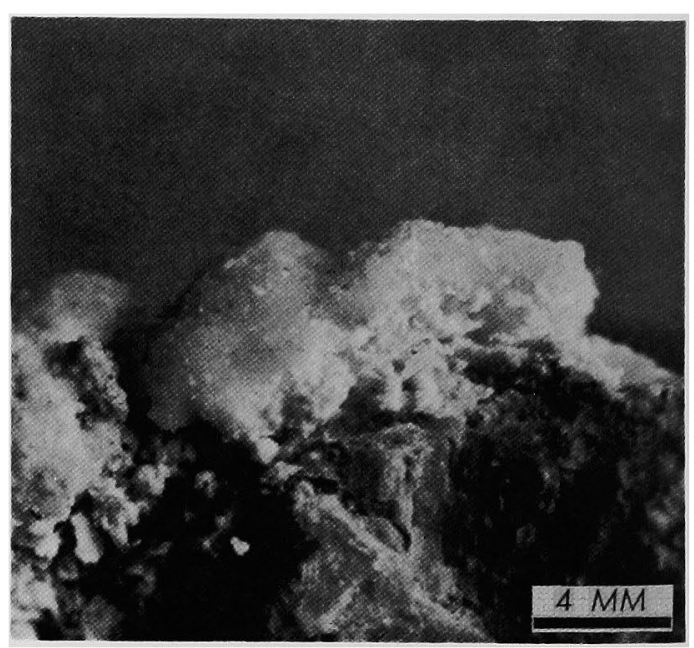

Fig. 2. Nesquehonite covering the encrustments of "yoshikawaite." 
Nesquehonite from Yoshikawa, Aichi Prefecture, Japan : Occurrence and thermal behaviour 277

Table 1. X-ray powder diffraction data for nesquehonite from Yoshikawa, Aichi Prefecture, Japan.

\begin{tabular}{|c|c|c|c|c|c|c|c|}
\hline \multicolumn{2}{|c|}{ Room temperature } & \multicolumn{2}{|c|}{$60^{\circ} \mathrm{C}$} & \multicolumn{2}{|c|}{$100^{\circ} \mathrm{C}$} & \multicolumn{2}{|c|}{$440^{\circ} \mathrm{C}$} \\
\hline $\mathrm{d}$ & $I / I_{0}$ & d & $I / I_{0}$ & $\mathrm{~d}$ & $I / I_{0}$ & $\mathrm{~d}$ & $I / I_{0}$ \\
\hline 6.544 & 100 & 6.520 & 100 & $5.258 \mathrm{~b}$ & 100 & 6.050 & 100 \\
\hline 6.067 & 3 & 6.071 & 3 & 3.844 & 11 & 4.272 & 10 \\
\hline 4.928 & 5 & 4.923 & 4 & $3.254 \mathrm{~b}$ & 34 & 3.489 & 57 \\
\hline 4.158 & 3 & 4.162 & 4 & $2.775 \mathrm{~b}$ & 75 & 3.018 & 16 \\
\hline 3.865 & 98 & 3.860 & 97 & 2.619 & 41 & 2.698 & 7 \\
\hline 3.593 & 24 & 3.590 & 22 & 2.332 & 7 & 2.464 & 7 \\
\hline 3.227 & 18 & 3.241 & 17 & 2.144 & 2 & 2.282 & 33 \\
\hline 3.038 & 40 & 3.037 & 33 & 1.8607 & 27 & 2.134 & 72 \\
\hline 2.987 & 10 & 2.986 & 9 & 1.7262 & 11 & 2.012 & 21 \\
\hline 2.789 & 20 & 2.875 & 17 & & & 1.9073 & 13 \\
\hline 2.627 & 18 & 2.625 & 20 & & & 1.8193 & 13 \\
\hline 2.514 & 41 & 2.512 & 34 & \multirow{2}{*}{\multicolumn{2}{|c|}{$180^{\circ} \mathrm{C}$}} & 1.7423 & 5 \\
\hline 2.328 & 5 & 2.341 & 5 & & & 1.6743 & 10 \\
\hline 2.318 & 3 & 2.315 & 2 & \multirow{9}{*}{$\begin{array}{l}5.203 \mathrm{~b} \\
3.243 \mathrm{~b} \\
2.804 \mathrm{~b} \\
2.764 \mathrm{~b} \\
2.621 \mathrm{~b} \\
1.858 \mathrm{~b}\end{array}$} & & 1.5564 & 8 \\
\hline 2.176 & 14 & 2.203 & 3 & & 100 & 1.5062 & 28 \\
\hline 2.127 & 3 & 2.175 & 11 & & 62 & 1.4629 & 13 \\
\hline 2.023 & 13 & 2.126 & 3 & & 54 & 1.4202 & 7 \\
\hline 1.9294 & 34 & 2. 222 & 10 & & 92 & 1.3847 & 7 \\
\hline 1.8953 & 3 & 1.9275 & 28 & & 46 & 1.3171 & 5 \\
\hline 1.8483 & 6 & 1.8943 & 2 & & 31 & & \\
\hline 1.8382 & 6 & 1.8466 & 5 & & & & \\
\hline 1.8025 & 12 & 1.8385 & 5 & & & & \\
\hline 1.7764 & 2 & 1.8009 & 10 & \multirow{2}{*}{\multicolumn{2}{|c|}{$350^{\circ} \mathrm{C}$}} & \multirow{2}{*}{\multicolumn{2}{|c|}{$500^{\circ} \mathrm{C}$}} \\
\hline 1.7277 & 2 & 1.7751 & 3 & & & & \\
\hline 1.7208 & 3 & 1.7265 & 4 & \multirow[b]{2}{*}{6.042} & & \multirow{7}{*}{$\begin{array}{l}2.442 \\
2.118 \\
1.4986 \\
1.2765\end{array}$} & \multirow{7}{*}{$\begin{array}{r}9 \\
100 \\
53 \\
6\end{array}$} \\
\hline 1.6510 & 7 & 1.7181 & 4 & & 100 & & \\
\hline 1.6345 & 3 & 1.6587 & 2 & 4.266 & 10 & & \\
\hline 1.6211 & 3 & 1.6496 & 7 & 3.488 & 66 & & \\
\hline 1.5861 & 2 & 1.6337 & 3 & 3.019 & 20 & & \\
\hline 1.5545 & 4 & 1.6211 & 2 & 2.702 & 11 & & \\
\hline 1.5295 & 2 & 1.5881 & 2 & 2.462 & 14 & & \\
\hline 1.5073 & 2 & 1.5535 & 4 & 2.283 & 43 & \multirow{2}{*}{\multicolumn{2}{|c|}{$\left(520^{\circ} \mathrm{C} *\right)$}} \\
\hline 1.4584 & 2 & 1.5291 & 2 & 2.135 & 50 & & \\
\hline 1.4342 & 2 & 1.5082 & 2 & 2.012 & 18 & & \\
\hline 1.4000 & 2 & 1.4588 & 1 & 1.9095 & 14 & 4.806 & 23 \\
\hline 1.3854 & 2 & 1.4340 & 2 & 1.8190 & 11 & 2.449 & 12 \\
\hline 1.3204 & 2 & & & 1.7420 & 7 & 2.373 & 37 \\
\hline 1.3123 & 2 & & & 1.6729 & 10 & 2.118 & 100 \\
\hline 1.2847 & 2 & & & 1.5576 & 10 & 1.7979 & 14 \\
\hline I. 2588 & 2 & & & 1.5084 & 10 & 1.5721 & 14 \\
\hline 1.2492 & 2 & & & 1.4633 & 11 & 1.4957 & 58 \\
\hline & & & & 1.4219 & 11 & & \\
\hline & & & & 1.3816 & 10 & & \\
\hline & & & & 1.3502 & 7 & & \\
\hline
\end{tabular}

* Left alone at room temperature for three months after heated to $520^{\circ} \mathrm{C}$. 

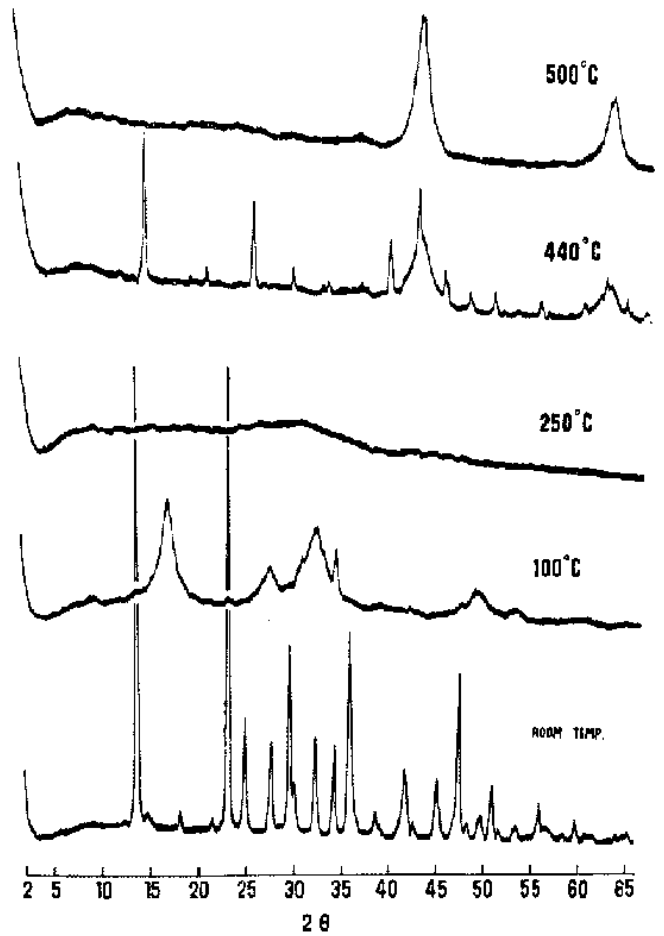

Fig. 3. X-ray diffraction patterns for nesquehonite and its thermal decomposition products. $\mathrm{CuK}_{\alpha}$ radiation was used for $2 \theta$.

occurs in association with only "yoshikawaite" and not with brucite and any other carbonate hydrate minerals.

\section{X-Ray Data}

$\mathrm{CuK}_{\alpha}$ radiation was used. The thermal effects on the whole X-ray diffraction patterns of nesquehonite are shown in Table 1 and Fig. 3. It is heated in air for about 10 to 20 minutes at each 10 or $20^{\circ} \mathrm{C}$ interval between 40 and $520^{\circ} \mathrm{C}$ on the Pt-heating stage of the high temperature X-ray diffraction apparatus. All measurements were made for the specimens cooled to room temperature after heating. Four decomposed phases are recognized with rising temperature. The first is the dehydrate phase which appears at $80^{\circ} \mathrm{C}$. At about $100^{\circ} \mathrm{C}$ it has the strongest reflection peak for $16.9^{\circ}$ $(2 \theta)$. Above this temperature the peak decreases in height gradually and completely disappears at least at $230^{\circ} \mathrm{C}$, showing the formation of amorphous phase (the second phase). The dehydrate phase has generally broad peaks, whose reflection lines are mostly inherited from those of nesquehonite, and the lattice is slightly contracted with rising temperature. The third is the decarbonate phase and will be discussed in later section. It appears at $280^{\circ} \mathrm{C}$ showing very sharp lines, and disappears suddenly at $490^{\circ}$ C. Periclase, the fourth phase, begins to appear at $370^{\circ} \mathrm{C}$ and increases gradually in crystallinity with rising temperature, followed by slight contraction of the lattice. However, magnesite is not recognized throughout the decomposition process.

The periclase formed from nesquehonite by heating up to $520^{\circ} \mathrm{C}$ was left alone in air at room temperature for about three months, whose diffraction datum is given in the last column of Table 1. A few new reflection lines appear together with those of periclase. The reproduced phase shows the d-spacing similar to that of brucite.

\section{Thermal Analysis}

Simultaneous DTA and TG curves of nesquehonite are shown in Fig. 4, together with that of the periclase from the $520^{\circ} \mathrm{C}$ heated nesquehonite, mentioned in the above section. The heating rate is $10^{\circ} \mathrm{C}$ per minute in air. There are six endothermic reactions, $132,176,216,420,507$ and $526^{\circ} \mathrm{C}$, and an exothermic reaction at $499^{\circ} \mathrm{C}$. The endotherm at $486^{\circ} \mathrm{C}$ is considered to be due to the coupling of the endothermic reaction at $507^{\circ} \mathrm{C}$ and the very rapid exothermic reaction at $499^{\circ} \mathrm{C}$.

TG curve shows the continuous weight 

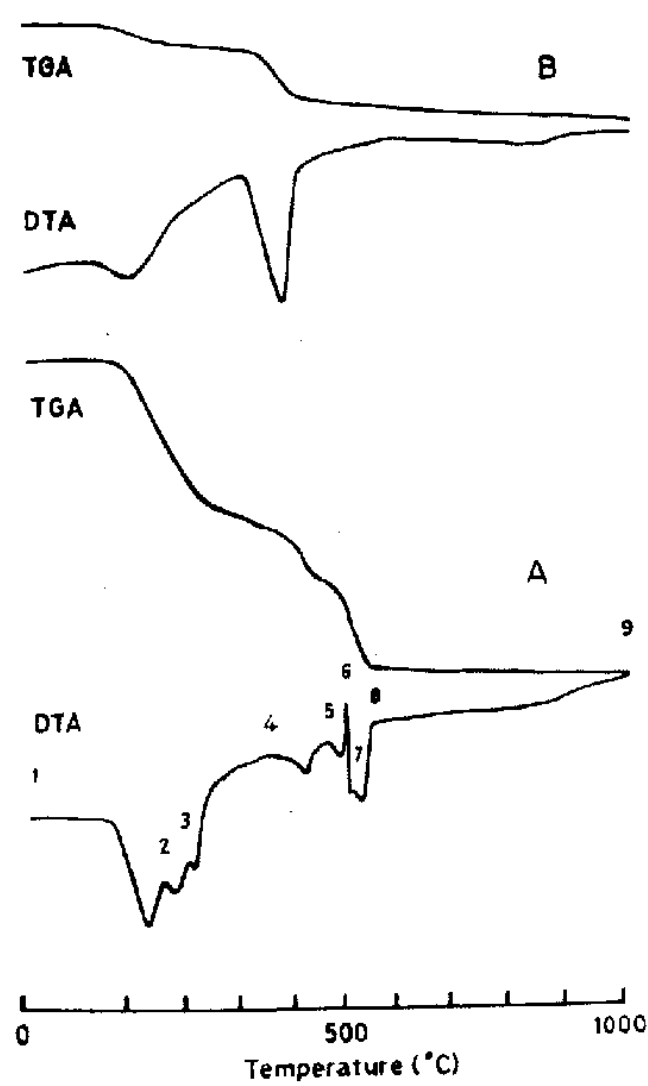

Fig. 4. DTA-TG patterns: A, nesquehonite; $B$, periclase from the $520^{\circ} \mathrm{C}$-heated nesquehonite. The heating rate is $10^{\circ} \mathrm{C} / \mathrm{min}$.

Table 2. The thermal decomposition products of nesquehonite at various temperatures between room temperature and $1000^{\circ} \mathrm{C}$ in air. The heating rate $10^{\circ} \mathrm{C}$ per minute.

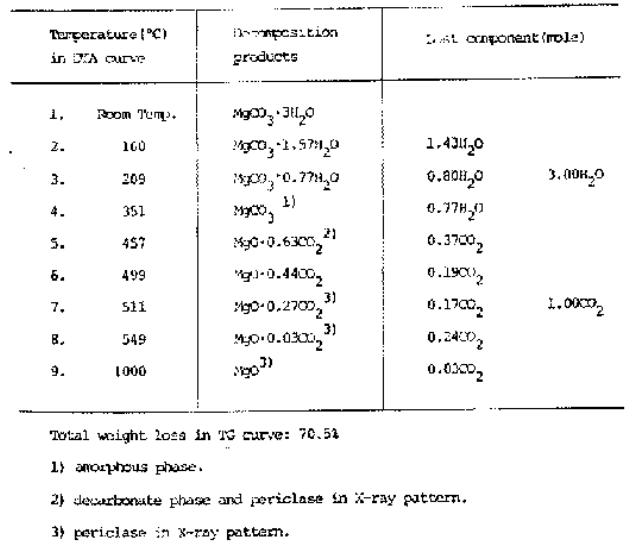

loss untill the last reaction is completed. Judging from the first appearance of periclase in the $\mathrm{X}$-ray pattern at $370^{\circ} \mathrm{C}$, the three endotherms at lower temperature region are related to the escape of $\mathrm{H}_{2} \mathrm{O}$, and the other three at higher temperature region to the escape of $\mathrm{CO}_{2}$. If the weight loss for each endothermic reaction is estimated from the TG curve for each temperature range, shown an the DTA curve of Fig. 4, the variations in the chemical compositions of the residuals through each reaction with rising temperature may be suggested as shown in Table 2. There is very slight weight loss towards higher temperature even after the last endothermic reaction is finished at about $550^{\circ} \mathrm{C}$. It attains about 0.03 mole ratio of $\mathrm{CO}_{2}$ at $1000^{\circ} \mathrm{C}$. This weight loss may be regarded as an observational епто. However, it is significant to note that the periclase from nesquehonite heated even up to $1000^{\circ} \mathrm{C}$ is also chemically active and is found to adsorb some amounts of $\mathrm{H}_{2} \mathrm{O}$ and $\mathrm{CO}_{2}$ at room temperature. The periclase from the $520^{\circ} \mathrm{C}$-heated nesquehonite, left alone in air at room temperature for about three months, shows a characteristic DTA-TG curve as shown in Fig. 4. There occur two endotherms at 102 and $385^{\circ} \mathrm{C}$, respectively. The former reaction is caused by the escape of $\mathrm{H}_{2} \mathrm{O}$ and the latter by the escape of $\mathrm{CO}_{2}$. The total weight loss is $28.6 \%$, made up as follows: $7.8 \%$ of $\mathrm{H}_{2} \mathrm{O}$ and $20.8 \%$ of $\mathrm{CO}_{2}$, respectively.

A few DTA curves by the various heating rates have been reported. The pattern in this paper is rather similar to that by Morandi (1969), except a few differences. He showed the endotherms at 160, 190, 220, 430 and $525^{\circ} \mathrm{C}$, and the exotherm at $515^{\circ} \mathrm{C}$. The first two endotherms are higher than those in this paper. The exotherm in his 
paper is conspicuously strong unlike those reported by the other workers. All endotherms below $300^{\circ} \mathrm{C}$ are generally attributed to the escape of $\mathrm{H}_{2} \mathrm{O}$. Beck (1950) and Morandi (1969) assigned the endotherm at about $430^{\circ} \mathrm{C}$ to the escape of $\mathrm{OH}$. However, judging from the detailed investigation of the TG curve, it may be safe to attribute the endotherm to the escape of $\mathrm{CO}_{2}$. This is also supported by the appearance of periclase on X-ray diffraction patterns even at $370^{\circ} \mathrm{C}$. Therefore, the third phase is considered to be the decarbonate. The endotherm around $520^{\circ} \mathrm{C}$ has been attributed to the escape of $\mathrm{CO}_{2}$. The nesquehonite from Yoshikawa shows two coupled endotherms at 507 and $526^{\circ} \mathrm{C}$, respectively, both of which are from the escape of $\mathrm{CO}_{2}$. But the former reaction is very complicated, as it is coupled with the exothermic one. After all, nesquehonite from this area is thermally decomposed to periclase through the three steps of the escape of $\mathrm{H}_{2} \mathrm{O}$ and those of $\mathrm{CO}_{2}$, respectively.

\section{INFRARED ABSORPTION SPECTRA}

The infrared spectra of nesquehonite and its heated samples are shown in Fig. 5 and the frequencies of the absorption bands in Table 3. The heated ones are the same as those used for the $\mathrm{X}$-ray diffraction. All measurements were made at room temperature by the $\mathrm{KBr}$ disc technique. The two extra bands at 3670 and $3620 \mathrm{~cm}^{-1}$ indicated by asterisks for non-treated nesquehonite are due to the admixed chrysotile and "yoshikawaite," respectively. Since purified samples were used for heating experiment, the two extra bands do not appear on the other spectra.

Characteristic changes in the thermal decomposition will be described for each range of the frequencies.

(A) 4000 to $2000 \mathrm{~cm}^{-1}$

A sharp and strong absorption band at $3540 \mathrm{~cm}^{-1}$ for the non-treated nesquehonite is due to the vibration of $\mathrm{O}-\mathrm{H}$ stretching and disappears at $60^{\circ} \mathrm{C}$. A sharp band at $3550 \mathrm{~cm}^{-1}$ is observed at $60^{\circ} \mathrm{C}$ and as a shoulder at $100^{\circ} \mathrm{C}$. Very sharp bands at $3680 \mathrm{~cm}^{-1}$ are found for the samples heated at 440 and $500^{\circ} \mathrm{C}$. The absorption is clearly caused by the water adsorbed by the periclase formed from nesquehonite. A sharp

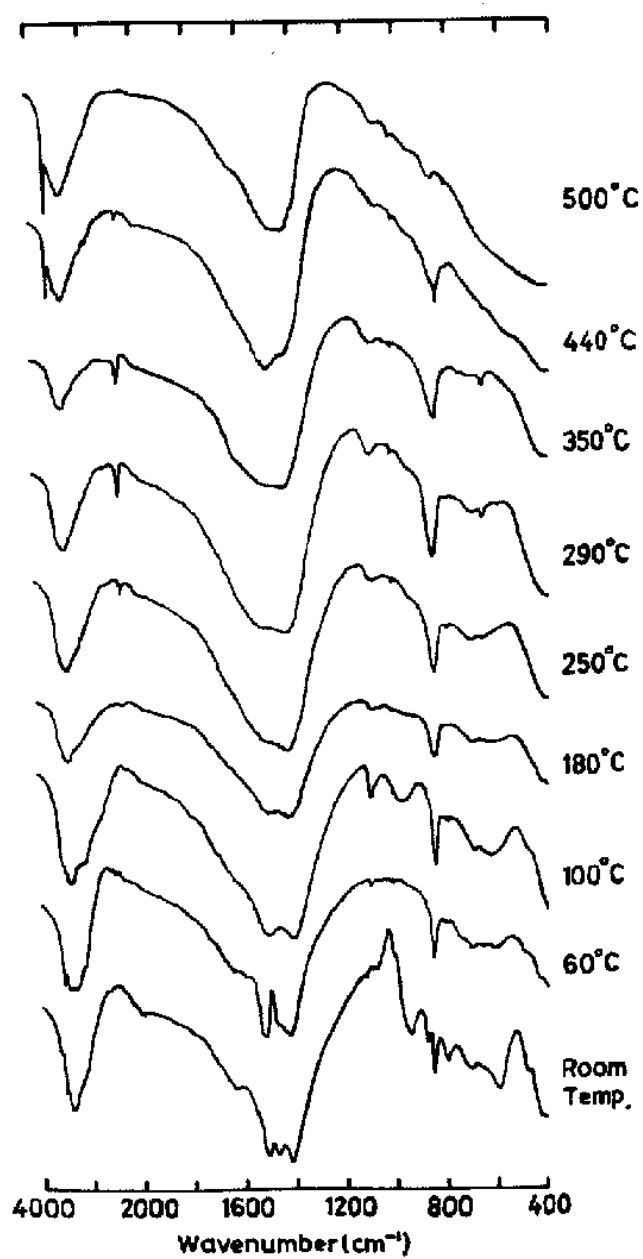

Fig. 5. Infrared absorption spectra of nesquehonite and the minerals heated at various temperatures. 
Nesquehonite from Yoshikawa, Aichi Prefecture, Japan : Occurrence and thermal behaviour 281

Table 3. Infrared absorption data for nesquehonite from Yoshikawa, Aichi Prefecture.

\begin{tabular}{|c|c|c|c|c|c|c|c|c|c|c|c|c|c|c|c|c|c|}
\hline \multicolumn{2}{|c|}{ irom Temp. } & \multicolumn{2}{|l|}{$60^{\circ} \mathrm{C}$} & \multicolumn{2}{|l|}{$100^{\circ} \mathrm{C}$} & \multicolumn{2}{|l|}{$180^{\circ} \mathrm{C}$} & \multicolumn{2}{|l|}{$250^{\circ} \mathrm{C}$} & \multicolumn{2}{|l|}{$290^{\circ} \mathrm{C}$} & \multicolumn{2}{|l|}{$350^{\circ} \mathrm{C}$} & \multicolumn{2}{|l|}{$440^{\circ} \mathrm{C}$} & \multicolumn{2}{|l|}{$500^{\circ} \mathrm{C}$} \\
\hline $3670^{*}$ & $w$ & 3550 & $\pi$ & 3550 & ww & $3410 \mathrm{~b}$ & $s$ & $3410 \mathrm{~b}$ & $\mathrm{~s}$ & 3675 & vw & 3675 & vw & 3680 & $\mathbf{5}$ & 3680 & $s$ \\
\hline $3620 * *$ & $w$ & 3430 & vw & $3395 \mathrm{~b}$ & $\mathbf{s}$ & $1505 \mathrm{~b}$ & $w$ & $2630 \mathrm{~b}$ & $w$ & $3410 \mathrm{~b}$ & & $3415 \mathrm{~b}$ & $m$ & $3405 \mathrm{~b}$ & $\mathrm{~s}$ & $3400 \mathrm{~b}$ & $\mathbf{s}$ \\
\hline 3540 & w & $3325 b$ & $\mathbf{s}$ & $3110 \mathrm{~b}$ & w & $1420 \mathrm{~b}$ & $\mathrm{~s}$ & 2380 & $v w$ & $2640 \mathrm{~b}$ & vw & 2930 & $\mathrm{vw}$ & 2930 & $v$ & $1450 \mathrm{~b}$ & $\mathbf{s}$ \\
\hline 3410 & s & 3150 & ww & 2505 & $w$ & $1104 \mathrm{~b}$ & $w$ & 2340 & $w$ & 2380 & vw & 2850 & ww & 2850 & $w$ & 1385 & $\omega$ \\
\hline 3130 & vw & 2625 & uw & $150 \mathrm{~B} \mathrm{~b}$ & s & 1010 & $w$ & $1.424 \mathrm{~b}$ & $\mathbf{s}$ & 2350 & $\mathrm{~m}$ & $2630 \mathrm{~b}$ & $w$ & 2380 & $w$ & $1075 \mathrm{~b}$ & $w$ \\
\hline 2610 & vw & 2515 & vw & $2403 \mathrm{~b}$ & s & 851 & $\mathrm{~m}$ & $1094 \mathrm{~b}$ & $w$ & $1422 \mathrm{~b}$ & s & 2380 & ww & 2350 & $w$ & 1015 & w \\
\hline 2500 & vw & 1640 & $w$ & 1104 & ni & $705 \mathrm{~b}$ & $w$ & 1014 & w & $1094 \mathrm{~b}$ & $w$ & 2350 & $m$ & $1498 \mathrm{~b}$ & $w$ & 950 & $v w$ \\
\hline 1639 & $\mathrm{vw}$ & 1587 & w & 1010 & vw & & & 854 & $\mathrm{~m}$ & 1014 & $w$ & $1.430 \mathrm{~b}$ & $s$ & $1422 \mathrm{~b}$ & s & $860 \mathrm{~b}$ & $w$ \\
\hline 1555 & $\mathrm{vw}$ & 1560 & w & $980 \mathrm{~b}$ & $m$ & & & 705 i & $w$ & 856 & $\mathrm{~m}$ & $1098 \mathrm{~b}$ & $w$ & 2130 & vw & & \\
\hline 1540 & ww & 1543 & w & 980 & $w$ & & & 660 & $w$ & $709 \mathrm{~b}$ & $w$ & 1014 & $w$ & $1079 \mathrm{~b}$ & $\mathrm{w}$ & & \\
\hline 1513 & $s$ & 1520 & $\$$ & 846 & $m$ & & & & & 661 & $w$ & 853 & nw & 1026 & $w$ & & \\
\hline 1474 & $s$ & 1468 & ww & 693 & $\mathrm{~m}$ & & & & & & & 844 & $\mathrm{~m}$ & 845 & $\mathrm{~m}$ & & \\
\hline 1418 & $\mathbf{s}$ & 1422 & $\$$ & $630 \mathrm{~b}$ & $\mathrm{~m}$ & & & & & & & $710 \mathrm{~b}$ & $w$ & & & & \\
\hline 1117 & $w$ & 1099 & $w$ & & & & & & & & & 660 & $w$ & & & & \\
\hline 1095 & $w$ & 1014 & $w$ & & & & & & & & & & & & & & \\
\hline 1013 & $w$ & 854 & $\mathrm{~m}$ & & & & & & & & & & & & & & \\
\hline $948 \mathrm{~b}$ & $\mathrm{~m}$ & 704 & $w$ & & & & & & & & & & & & & & \\
\hline 878 & $w$ & $657 \mathrm{~b}$ & $w$ & & & & & & & & & & & & & & \\
\hline 849 & $\mathrm{~m}$ & $610 \mathrm{~b}$ & $w$ & & & & & & & & & & & & & & \\
\hline $797 \mathrm{~b}$ & w & 494 & wr & & & & & & & & & & & & & & \\
\hline b 707 & $w$ & & & & & & & & & & & & & & & & \\
\hline 595 & m & & & & & & & & & & & & & & & & \\
\hline 481 & พ & & & & & & & & & & & & & & & & \\
\hline
\end{tabular}

* Chrysotile, ** "Yoshikawaite"

band at $2350 \mathrm{~cm}^{-1}$ and the shoulder at 2380 $\mathrm{cm}^{-1}$ appear at least at $250^{\circ} \mathrm{C}$, increasing in intensity above this temperature, and disappear below $500^{\circ} \mathrm{C}$. Since this temperature range is assigned to the amorphous phase and the decarbonate phase, the two absorption bands are derived from newly formed bonding in the decarbonate phase. It is noted that this new bonding is already formed in the amorphous phase at $250^{\circ} \mathrm{C}$. Furthermore, an indication of this bonding is seen even at $180^{\circ} \mathrm{C}$ as a weak and broad band. The intensity of this band increases at 290 to $350^{\circ} \mathrm{C}$, though the frequency is somewhat less by about $15 \mathrm{~cm}^{-1}$ Two sharp but weak absorptions at 2930 and $2850 \mathrm{~cm}^{-1}$ may probably belong to the decarbonate phase, since no absorption is found in the same frequency region for the sample heated at $500^{\circ} \mathrm{C}$. Or, they might be attri- buted to the water adsorbed into $\mathrm{KBr}$ from the decarbonate phase rather than from periclase, although this phase does not show any signs of adsorption of water in the Xray diffraction pattern.

(B) 2000 to $1300 \mathrm{~cm}^{-1}$

Four distinct absorption bands at 1639 , 1513,1474 and $1418 \mathrm{~cm}^{-1}$ are observed at room temperature. All bands become diffused with rising temperature. A band by $\mathrm{H}$ $\mathrm{O}-\mathrm{H}$ bending appears at $1639 \mathrm{~cm},-1$ and disappears at least at $100^{\circ} \mathrm{C}$. The band at $1474 \mathrm{~cm}^{-1}$ is not distinctly observed at $60^{\circ} \mathrm{C}$. The other absorption bands at 1513 and $1418 \mathrm{~cm}^{-1}$ become broad with rising temperature. Newly formed bands are observed at $1587 \mathrm{~cm}^{-1}$ at $60^{\circ} \mathrm{C}$ and $1385 \mathrm{~cm}^{-1}$ at $500^{\circ} \mathrm{C}$. The latter is a diagnostic one for the periclase from the heated nesquehonite, in which a large amount of $\mathrm{H}_{2} \mathrm{O}$ and $\mathrm{CO}_{2}$ 
is adsorbed.

White (1971) showed three bands at 1518,1470 and $1415 \mathrm{~cm}^{-1}$ to be caused by the absorption of $\mathrm{CO}_{3}^{2-}$ stretching. However, it is interesting to note that all bands become gradually diffused with rising temperature, in spite of the fact that the decarbonate phase shows higher crystallinity in $\mathrm{X}$-ray diffraction patterns.

(C) 1300 to $800 \mathrm{~cm}^{-1}$

The dehydrate phase, the decarbonate phase and the periclase from the heated nesquehonite are characterized by the broad bands at 980,1094 and $1075 \mathrm{~cm}^{-1}$, respectively. The absorption at $1095 \mathrm{~cm}^{-1}$ probably by $\mathrm{CO}_{3}^{2-}$ stretching in thermally nontreated nesquehonite is stronger at $100^{\circ} \mathrm{C}$ than those below this temperature, and then become broad with rising temperature. The bands at 948 and $878 \mathrm{~cm}^{-1}$ disappear completely at 60 and $180^{\circ} \mathrm{C}$, respectively. The latter band may correspond to that of "yoshikawaite." However, it should be attributed to nesquehonite, because the "yoshikawaite" heated to $180^{\circ} \mathrm{C}$ shows the bands as strong as that at room temperature. The sharp band at $849 \mathrm{~cm}^{-1}$ by $\mathrm{CO}_{3}^{2-}$ bending becomes broad with rising temperature up to $440^{\circ} \mathrm{C}$. Another characteristic band of the periclase from the heated nesquehonite is observed at $860 \mathrm{~cm}^{-1}$.
(D) 800 to $400 \mathrm{~cm}^{-1}$

The absorption spectra in this frequency region change rapidly with rising temperature. All bands become broad even at $60^{\circ} \mathrm{C}$. The dehydrate phase and the decarbonate phase are characterized by the bands at 630 and $660 \mathrm{~cm}^{-1}$, respectively. The periclase from the heated nesquehonite does not show any distinguishable absorption spectrum. The band at $797 \mathrm{~cm}^{-1}$ is also compatible with that of "yoshikawaite." But, judging from the same reason as mentioned above, it is also ascribed to the absorption by nesquehonite.

\section{Discussions}

Some intermediate products through the thermal decomposition of nesquehonite have been reported by many workers. But all of these are not always crystalline by $\mathrm{X}$ ray diffraction. As mentioned above, three crystalline phases and an amorphous one are identified. A schematic representation of the thermal decomposition of this mineral may be compiled as in Fig. 6 .

The thermal decomposition of the sample heated for the X-ray diffraction is considered to proceed rapidly enough so as to form the metastable phases within ten to twenty minutes at various temperatures,

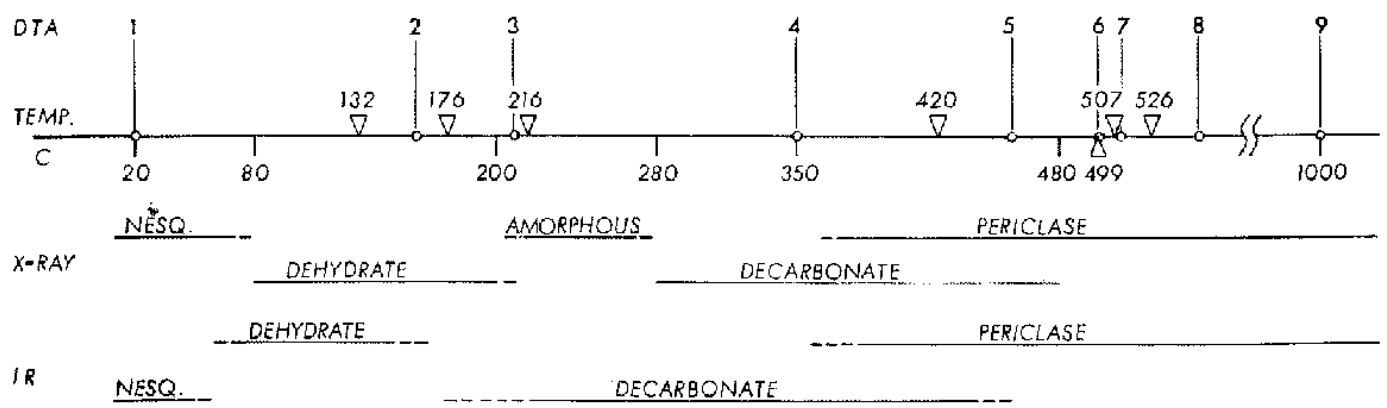

Fig. 6. Schematic diagram of the thermal decomposition of nesquehonite. $\nabla \& \Delta:$ endothermic and exothermic maxima, respectively. 0 : temperature on DTA curve. ESQ.: nesquehon ite. 
since even the sample held for more than 24 hours shows no significant change in the $\mathrm{X}$ ray pattern. The samples for DTA-TG weigh about 15 to $20 \mathrm{mg}$, but those for the $\mathrm{X}$-ray analyses about $1 \mathrm{~g}$. In both thermal treatments, the heating rates are approximately the same. Therefore, the "holding" effect on the larger amount of sample is considered to correspond to the continuous uprising of temperature for the less amount of sample for DTA-TG with the constant rate of $10^{\circ} \mathrm{C}$ per minute.

The chemical composition of the dehydrate phase changes gradually from $\mathrm{MgCO}_{3}$. $3 \mathrm{H}_{2} \mathrm{O}$ to $\mathrm{MgCO}_{3} \cdot 0.77 \mathrm{H}_{2} \mathrm{O}$ with rising temperature. However, three distinguishable endotherms with continuous weight loss are found on the DTA curve. Judging from. the X-ray patterns, this phase is related to the first two endotherms. As all the reflection lines become broad above $120^{\circ} \mathrm{C}$, the thermal condition below this temperature corresponds probably to the endothermic reaction of the maximum at $132^{\circ} \mathrm{C}$. Then, the broad peaks for each pattern gradually disappear with rising temperature through the endotherm at $176^{\circ} \mathrm{C}$, and the patterns of the amorphous phase appears.

The amorphous phase contains some amounts of $\mathrm{H}_{2} \mathrm{O}$, that is, 0.77 mole which is equal to $25.7 \%$ of total $\mathrm{H}_{2} \mathrm{O}$. It is continuously lost probably up to $351^{\circ} \mathrm{C}$, through the endotherm at $216^{\circ} \mathrm{C}$. However the decarbonate phase appears already at $280^{\circ} \mathrm{C}$ in the $\mathrm{X}$-ray pattern. As strikingly shown in the infrared spectra, the absorpw tion bands characterized by this phase are already observed even in the amorphous phase at $250^{\circ} \mathrm{C}$. Therefore, the formation of new chemical bonds suggestive of the decarbonate phase is distinctly proceeding in the amorphous phase. The decarbonate phase between 410 and $440^{\circ} \mathrm{C}$ shows the strongest peak heights of the $\mathrm{X}$-ray reflection lines, though the subsequent phase, periclase, is already formed in some amounts. The decrease in intensity of the absorption at $2350 \mathrm{~cm}^{-1}$ in the sample heated to $440^{\circ} \mathrm{C}$ is caused by the decrease in quantity due to its decomposition. It is completely decomposed by heating from 480 to $490^{\circ} \mathrm{C}$ without any diffused $\mathrm{X}$-ray patterns. This temperature range corresponds to the exothermic reaction of the maximum at $499^{\circ} \mathrm{C}$. Therefore, the decomposition is completed just before this exothermic reaction starts. The chemical composition of this phase is about $\mathrm{MgO} \cdot 0.44 \mathrm{CO}_{2}$ at $499^{\circ} \mathrm{C}$. Only periclase is observed in the $\mathrm{X}$-ray diffraction patterns above $490^{\circ} \mathrm{C}$, which show, however, broad reflection lines. It is interesting to note that some amounts of $\mathrm{CO}_{2}$ are contained in the periclase, and is released gradually with rising temperature up to $550^{\circ} \mathrm{C}$. Jurlging from the two distinct endotherms at 507 and $526^{\circ} \mathrm{C}$, the $\mathrm{CO}_{2}$ may be loosely joined to very fine-grained and less crystalline periclase by two somewhat different ways.

Explanations of the exothermic reaction have been discussed by many workers. The magnesium carbonate hydrate minerals are generally characterized by this exotherm and the subsequent endotherm. It is reported that this exotherm might be caused by the crystallization of periclase with a question mark added in the table (Beck, 1950). Morandi (1969) concluded that it is attributed to the formation of magnesite, based on the DTA data under $\mathrm{CO}_{2}$ condition. On the other hand, Iwai et al. (1969) suggested the abrupt contraction of the lattice of periclase through the process of increasing in crystallinity around $500^{\circ} \mathrm{C}$. As 
already mentioned above, magnesite is not recognized in air, and the lattice of periclase also contracts gradually with rising temperature. However, this exothermic reaction is drastic and even explosive, especially in hydromagnesite and "yoshikawaite." It might have been caused by some other reactions which can release a great amount of energy within a short time. Further study on this topic will be reported in the near future.

\section{AGKNOWLedgMent's}

Sincere appreciation is extended to Dr. K. Sakurai for giving a private communication about the informations on some magnesium carbonate hydrate minerals from the serpentinites in Japan. Thanks are due to Professor I. Sunagawa of Tohoku University for kind advice, Dr. H. Nakata of the Department of Chemistry, Aichi University of Education, and Dr. S. Matsuura of the Department of General Education, Nagoya University for kindly assisting in the interpretation of infrared spectra, and Mrs. Sugimoto for translation of Morandi's paper into English.

\section{REFERENGES}

Beck, C.W. (1950), Differential thermal analysis curves of carbonate minerals. Am. Mineral., 35. $985-1013$.

Fischbeck, R. and Müller, G. (1971), Monohydrocalcite, hydromagnesite, nesquehonite, dolomite, aragonite, and calcite in speleotherms of the Fränkische Schweiz, West Germany, Contr. Miner. Petrol., 33, 87-92.

Iwai, S., Murotani, H., Morikawa, H. and Aoki, H. (1969). Thermal decomposition of $\mathrm{MgCO}_{3} \cdot 3 \mathrm{H}_{2} \mathrm{O}$. (in Japanese with English abstract), YogyoKyokai-Shi, 77, 25-31.

Marschner, H. (1969), Hydrocalcite $\left(\mathrm{CaCO}_{\mathrm{g}} \cdot \mathrm{H}_{\mathbf{2}} \mathrm{O}\right)$ and nesquehonite $\left(\mathrm{MgCO}_{3}, 3 \mathrm{H}_{2} \mathrm{O}\right)$ in carbonate scales. Science, 165, 1119-1121.

Morandi, N. (1969), La dissociazione termica dell 'idro-magnesite e della nesquehonite. Miner. Petrogr. Acta, 15, 93-108.

Stephan, G.W. and Macgillavry, C.H. (1972), The crystal structure of nesquehonite, $\mathrm{MgCO}_{8}$. $3 \mathrm{H}_{2} \mathrm{O}$. Acta Cryst., B28, 1031-1033.

Suzuki, J. and Ito, M. (1973), A new magnesium carbonate hydrate mineral, $\mathrm{Mg}_{5}\left(\mathrm{CO}_{3}\right)_{4}(\mathrm{OH}\rangle_{2}$. $\mathrm{8H}_{2} \mathrm{O}$, from Yoshikawa, Aichi Prefecture, Japan. I. Japan. Assoc. Min. Petr. Econ. Geol., 68, 353-361.

Towe, K.M. and Malone, P.G. (1970), Precipitation of carbonate phase from seawater. Nature, 226, 348-349.

White, W.B. (1971), Infrared characterization of water and hydroxyl ion in the basic magnesium carbonate minerals. Am. Mineral., 56, 46-53.

Winchell, A.N. and Winchell, H. (1951), Elements of optical mineralogy, part II. 4th ed., John Wiley \& Sons, inc., New York.

\section{愛知県吉川産 nesquehonite}

\section{鉿木 重人，伊藤 正裕}

Nesquehonite $\left(\mathrm{MgCO}_{3} \cdot 3 \mathrm{H}_{2} \mathrm{O}\right)$ が，含ブルーサイト蛇紋岩の風化面を覆ら “yoshikawaite” の表面から発見 され、X線回折就上び光学的性質に基づき同定された。無色透明の柱状結晶をなす。本鉣物は，温度の上年化

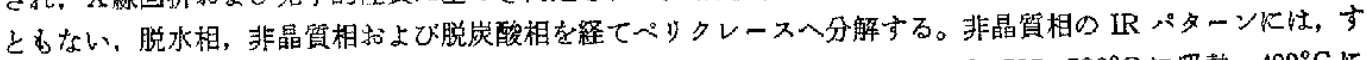

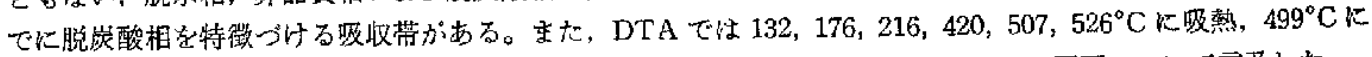
発熱去す。この発熱反応は，含水マグネシウム炭酸塩鉱物群㐳共通しており，この原因について言及した。 